\title{
CONFLITO AMBIENTAL NA COSTA DE SÃO PAULO: O PLANO DIRETOR DE SÃO SEBASTIÃO
}

\author{
Icaro A. da Cunha*
}

\begin{abstract}
RESUMO: A visão dos problemas ambientais como conflitos entre diferentes atores sociais rejeita uma simplificadora oposição entre o "natural" e as ações "antrópicas", que generaliza para o conjunto da sociedade padrões predatórios de transformação do meio ambiente. Ao falar-se de conflitos ambientais, reconhece-se diferentes projetos de relação sociedade - natureza e interesses imediatos diversos, associados aos vários usos possíveis dos recursos ambientais. Abre-se o caminho para que a própria dinâmica destes conflitos seja entendida como fator de construção da sustentabilidade. Este texto procura documentar e discutir um episódio de conflito ambiental, tomando a experiência de discussão pública, negociação e votação do Plano Diretor Municipal de São Sebastião, município da costa norte de São Paulo. Pretende-se discutir o avanço possivel em termos de mediação de conflitos, com utilização de técnicas de negociação, e a relação deste processo com a dinâmica da política local, em especial marcando os papéis do Executivo e do Legislativo no processo participativo. O principal tema que emerge em relação à pauta da sustentabilidade é a competição entre o turismo e o veranismo na ocupação do território costeiro.
\end{abstract}

PALAVRAS-CHAVE: conflito ambiental; sustentabilidade e negociação de conflitos; turismo e conflito ambiental

* Sociólogo, Doutor em Saúde Ambiental. Pesquisador bolsista da FAPESP junto ao Programa de Pós Graduação de Ciência Ambiental da USP. Telefone 2583862 R. Alagoas 212 ap. 64 
A evolução da discussão sobre desenvolvimento e meio ambiente permite hoje apoiar em sólida argumentação a idéia de que os problemas ambientais, longe de contraporem genericamente as pessoas e a natureza, se constituem em conflitos sociais, que alinham distintos grupos humanos que pretendem diferentes utilizações dos recursos ambientais (IBASE, 1995). Compreendendo a relação sociedade/natureza como um fenômeno de resultantes mutáveis em função das técnicas produtivas utilizadas (HOGAN, 1992, BECKER, 1992), é possivel fugir ao dilema tradicional que consiste em optar entre progresso ou preservação, uma visão comum, com sinais trocados, a desenvolvimentistas e alguns setores ecologistas da fase do Brasil potência perseguido pelos governos militares. A alternativa é a construção da idéia de sustentabilidade ou ecodesenvolvimento, cujos dois principais termos são natureza transformada e economia repensada, de forma que ambas se sustentem no tempo (SACHS, 1986 e 1993).

A referência para um conceito de sustentabilidade são as definições do Relatório Brundtland em seu segundo capítulo (COMISSÃO MUNDIAL SOBRE AMBIENTE E DESENVOLVIMENTO, 1988). Atender às necessidades do presente sem comprometer a possibilidade de suprir as necessidades do futuro, é a formulação inicial que encerra dois termos absolutamente críticos em relação às práticas econômicas predominantes. Nas necessidades do presente, não se pode ignorar as necessidades básicas hoje não atendidas para todos: alimentos, roupas, habitação, empregos. A menção às necessidades do futuro destaca os limites ecológicos, cujo desrespeito e ultrapassagem impede que o desenvolvimento seja durável no tempo, por falta de sustentação nos processos naturais.

Assim, a proposta de "Nosso Futuro Comum" destaca a necessidade de rever os atuais padrões de consumo dos mais ricos - sejam os países mais desenvolvidos, sejam os setores ricos dentro de cada país - por serem insustentáveis. Deve-se buscar harmonizar a população com o potencial cambiante dos ecossistemas, no que se refere à evolução demográfica e à distribuição da população no espaço. As tecnologias devem ser empregadas com respeito aos limites ecossistêmicos e sem marginalizar amplos segmentos da população: o acesso aos recursos ambientais deve ser equitativo. Os recursos renováveis devem ser aproveitados de forma a garantir sua reposição, e para os não renováveis devem buscar-se alternativas antes de seu esgotamento, preservando-se o máximo de opções futuras. 
A extinção das espécies pode limitar as opções das futuras gerações, impondo-se portanto a conservação das espécies animais e vegetais. É fundamental controlar a geração de resíduos, pois sua liberação no ambiente afeta a disponibilidade e a qualidade de ar, água e outros elementos naturais, podendo comprometer a integridade global do ecossistema.

O conflito humano ganha centralidade, já que esta visão permite superar a opção entre nós, sociedade, e eles, bichos e plantas, para trazer para a discussão, definitivamente, as oposições de interesses sobre como aproveitar os recursos ambientais, a competição entre umas e outras formas de fazê-lo e os custos das transformações, as externalidades tradicionalmente repassadas a outrem na forma de poluição ou escassez.

Esta discussão abre um vasto campo teórico em que se buscam as melhores articulações entre os campos da economia e da ecologia. Em paralelo, dá lugar à compreensão da gestão ambiental como um processo de administração e negociação de conflitos. Ambos os campos são complementares: trata-se de buscar nexos - e contradições - gerais tanto quanto vislumbrar nos campos concretos das economias regionais, onde se desenvolvem certos tipos específicos de conflitos e complementaridades, as possibilidades de avanço para novas formas, mais sinérgicas, de articulação entre a lógica econômica e os limites ecológicos.

Lidar com a idéia de conflitos ambientais leva-nos a identificar os diferentes sujeitos da contraditória relação sociedade/natureza. Estes sujeitos, em função de sua força política relativa, serão mais ou menos capazes de sustentar as mudanças de rumo, identificadas como convenientes do ponto de vista ambiental. Num contexto democrático, esta é a condição para a sustentabilidade política das propostas de sustentabilidade ecológica, dimensão tão estratégica como bem destaca SACHS (1993). Como diz Guimarães, ..." hay que plantearse la pregunta: Cuales son los actores sociales promotores del desarrollo sustentable?" (GUIMARÃES, 1998).

\section{A NEGOCIAÇÃO DE CONFLITOS COMO BUSCA DA SUSTENTABILIDADE}

A negociação de conflitos, como via para operacionalizar, ou concretizar, a perspectiva de desenvolvimento sustentável, é uma proposta que surge trazida por diferentes autores. Um programa apoiado pelo governo holandes difunde técnicas de construção de 
consenso, desenvolvidas no Massachussets Institute of Technology e aplicadas a situações de conflito ambiental, como estratégia para enfrentar o desafio da sustentabilidade (SUSTAINABILITY CHALLENGE FOUNDATION, 1994). A negociação de conflitos como dimensão básica da gestão ambiental é uma idéia que tem guarida na CEPAL, como se vê em trabalhos como o de Dourojeanni (CEPAL 1993).

De forma geral, estas abordagens se assemelham ao propor como passos essenciais uma correta identificação dos interlocutores para formar mesas de negociação; a identificação de suas necessidades, motivações e interesses; a condução dos debates com procedimentos democráticos e respeitosos; procedimentos geradores de credibilidade por parte do(s) mediador(es), em que se destaca o fornecimento de informações confiáveis ; a construção de clima positivo para que se desenvolva uma pauta de transações entre os atores; a instituição de um processo de sucessivas negociações, em que se abandonam expectativas imediatistas por uma idéia de ganhos graduais.

Orienta esta abordagem a idéia de que é possivel construir consensos graduais e progressivos, em que ao contrário de estabelecer um jogo ganha-perde (uns ganham, outros perdem, resultados positivos e negativos se equilibrando numa conta global zero), se constrói um jogo de ganha - ganha, um jogo de soma positiva, resultante do enfoque dos ganhos mútuos (SUSSKIND E FIELD, 1996).

A proposta de criar um processo contínuo de negociação, com avanços progressivos e retomadas sucessivas das discussões, implica em conceber, de outro lado, a construção da sustentabilidade também como um processo gradual, em que a cada momento, em função do avanço da consciência dos diferentes setores, das melhorias técnicas, dos entendimentos entre atores, dos fatores de mercado (como a importância dos critérios de qualidade, por exemplo), progressos institucionais e outros, a sociedade aproxima-se mais de práticas que se enquadrem na conceituação de desenvolvimento sustentável.

É importante referir, ainda, o papel da negociação de conflitos no desenvolvimento de políticas públicas, à luz da revisão crítica do planejamento tradicional, feita por Matus. Analisando a inércia das máquinas governamentais na América Latina e a dificuldade de levar à prática plataformas políticas consagradas nas urnas por suas propostas de mudança nas ações governamentais, Matus identifica a raiz do fracasso dos governos em dois pontos principais: um planejamento tradicional, em que o sujeito é o governo e os demais atores, objetos da ação; e a distância entre comando político e planos técnicos. O comando político 
Saúde e Sociedade 10(1):15-31, 2001

lida com a realidade que é multifacetada, arena para os mais diversos interesses que produzem pressões contraditórias. Os setores técnicos compartimentam os problemas em questões setoriais. Assim, planos de governo não conseguem dar conta dos verdadeiros "problemas" que o governante precisa enfrentar, o que é agravado por não levar-se em conta adequadamente as óticas e os poderes de intervenção dos demais sujeitos da sociedade, fora do governo. O planejamento estratégico situacional, a alternativa proposta por Matus e adotada como uma referência em agências oficiais (FUNDAP,1988) conduz entre outras ferramentas complementares - a uma valorização da negociação de conflitos entre os diferentes atores interessados em determinadas situações, como um dos instrumentos para viabilização de políticas públicas (MATUS, 1996, 1997; HUERTAS, 1996).

\section{EVOLUÇÃO DOS CONFLITOS AMBIENTAIS EM SÃO SEBASTIÃO, COSTA NORTE DE SÃO PAULO}

As significativas manifestações de conflitos ambientais no município de São Sebastião, cenário dos episódios aqui discutidos, ligam-se a suas peculiaridades históricas e ambientais, tratando-se de um lugar que abriga conjuntos naturais e arquitetônicos de importância singular, fenômenos notáveis de devastação e poluição e uma consciência bastante disseminada na sociedade local sobre as possibilidades e conveniências de procurar manter-se uma qualidade ambiental diferenciada no contexto do litoral.

O território de São Sebastião contém grande porção de Serra do Mar coberta por Mata Atlântica, sendo cerca de 70 \% do município parte do Parque Estadual da Serra do Mar. Esta área protegida integra a Reserva da Biosfera da Mata Atlântica, contando com alto grau de endemismo de suas espécies (CÂMARA, 1992) , o que leva esta região a ser considerada uma área de "extrema importância biológica" no consenso de muitas das entidades interessadas na conservação deste bioma (SOS MATA ATLÂNTICA, 1999). Ao longo do município sucedem-se os avanços dos morros até o mar, deixando entre si anfiteatros onde ocorrem as praias e a planície costeira. A costa, de quase 100 quilômetros, desenvolve-se a partir do limite com Bertioga no sentido aproximado oeste- leste até a altura do início do Canal de São Sebastião, porto natural profundo entre o continente e a ilha de São Sebastião, pertencente ao município de Ilhabela. Aí a costa ganha o sentido aproximado sudeste - noroeste até o limite com Caraguatatuba. Para o interior, onde ocorrem as cristas da Serra, o município faz divisa com Salesópolis. Toda a zona costeira municipal, 
incluindo as várias ilhas marítimas, é objeto das ações do Programa de Gerenciamento Costeiro da Secretaria Estadual de Meio Ambiente. A feição urbana é bastante singular, dada a distribuição dos bairros ao longo da costa, ligados entre si por uma única via, a estrada Rio-Santos.

O atual quadro de conflitos ambientais se desenvolve com as fortes e generalizadas modificações provocadas pela rearticulação do município aos circuitos econômicos nacionais e internacionais nas décadas recentes, a partir de tres iniciativas centrais : a inauguração do porto de cargas, na segunda metade da década de 50; a implantação do Terminal Almirante Barroso, o maior terminal petrolífero da América Latina, na década de 60; e o asfaltamento da rodovia Rio-Santos, na década de 80. Conforma-se um novo ciclo de ocupação da costa, com todas as características predatórias percebidas por MORAES (1995) num processo liderado pelos grandes projetos de impacto e pela especulação imobiliária possibilitada pelas novas facilidades de acesso. Os acidentes ambientais com derramamento de óleo no mar, a poluição por esgotos, o desmatamento, o desalojo dos caiçaras e a descaracterização dos seus núcleos de moradia são as marcas registradas dessa fase marcada pela ausência de parâmetros ecológicos ou culturais.

Os conflitos ambientais eclodem na segunda metade dos anos 80, surgindo um movimento ambientalista local articulado com as ONGs de atuação estadual e nacional. A luta contra os derramamentos de petróleo é pauta central, mas também são episódios marcantes na história das lutas ambientalistas locais o confronto em torno da ampliação do Porto com aterro na área do Canal, em 1987; ou a participação na mobilização contra a chamada rodovia do Sol, em 1989, que resultou na não realização da obra (CUNHA, 1996).

Na década de 90, acompanhando o que ocorre em escala nacional com o movimento ambientalista brasileiro (VIOLA, 1992), posturas ambientalistas passam a ser incorporadas nas ações governamentais e ocorre uma diversificação de atores interessados nas questões de qualidade ambiental. Enquanto a administração municipal do período 89-92 desenvolvia uma política ambiental mais abrangente e agressiva (CUNHA, 1996), um Conselho Municipal de Meio Ambiente e Urbanismo, de composição paritária entre representantes do governo local e de entidades da sociedade civil, começava a tornar-se o fôro de articulação institucional dos conflitos ambientais. A participação deste Conselho na discussão das iniciativas de política ambiental daquele governo; o estilo amplamente participativo da discussão e apresentação de emendas à lei ambiental municipal então formulada, que veio a ser aprovada por unanimidade na Câmara Municipal; as primeiras experiências de licenciamento ambiental 
Saúde e Sociedade 10(1):15-31, 2001

pelo município com abertura de informações para a comunidade, como no caso das questões de riscos associados ao terminal da Petrobrás, são exemplos de uma dinâmica que ampliava o foco de um processo participativo inaugurado pelo programa de coleta seletiva do lixo doméstico, iniciado fora do governo e incorporado pela administração a partir da entusiástica adesão dos moradores (BLAUTH, 1990).

A composição do Conselho de urbanismo e meio ambiente (COMDURB) em 92 reconhecia os espaços reais ou potenciais de novos atores da sociedade civil. Já então, se fazia sentir o peso reivindicativo da federação das sociedades de amigos da costa sul, entidades que agregam os donos de residências de veraneio, que embora durante muito tempo fizessem - e ainda façam - parte de suas reuniões em São Paulo, começavam a acompanhar de perto a dinâmica política e administrativa local. As sociedades de amigos da costa norte, a Ordem dos Advogados do Brasil , a Associação de Engenheiros e Arquitetos, os sindicatos e associações de trabalhadores, a Associação Comercial, e, obviamente, o Movimento de Preservação de São Sebastião (MOPRESS), eram os demais membros não governamentais do conselho .

\section{O PLANO DIRETOR E A ESTRATÉGIA DE DISCUSSÃO PÚBLICA}

Depois de uma gestão municipal, de 1993 a 1996, em que aparentemente esta participação da comunidade era um processo incômodo - tendo o Conselho alternado tempos em que não era convocado com outros em que surgiam conflitos e cobranças em relação a ações do governo local - o COMDURB voltou a ser reconhecido como espaço articulador dos debates públicos de meio ambiente pelo governo iniciado em 1997.

Comprometida com propostas ambientalistas em sua plataforma de governo, a nova gestão trouxe o ex presidente do MOPRESS, tradicional grupo ecologista local, como Secretário de Meio Ambiente, e elencou, entre suas prioridades, a conclusão do Plano Diretor municipal.Ao final do primeiro ano da gestão, dispunha-se finalmente de um texto dado como concluido pela equipe técnica. A pequena equipe de planejamento da Prefeitura contara com apoio de consultoria especializada, e agregara no processo de elaboração um grupo de técnicos das diferentes secretarias municipais, encarregado de recolher contribuições setoriais. As principais bases de dados foram os levantamentos feitos para o macrozoneamento costeiro estadual, estudos geotécnicos feitos pelo Instituto Geológico para subsidiar as ações de Defesa Civil relativas a riscos naturais, dados do IBGE e subsídios 
setoriais. Pela primeira vez, surgiu uma base cartográfica do município. Embora pudesse ter alguma defasagem temporal nos dados disponíveis, o texto do Plano era um diagnóstico bem consistente sobre a inserção regional de São Sebastião e sobre as alternativas estratégicas para seu desenvolvimento com respeito às características ambientais do território e à dinâmica peculiar de sua população, que soma hoje 45000 pessoas, crescendo à base de $6 \%$ ao ano em função da forte migração, e mais até 80000 pessoas nas temporadas de verão. O trabalho vinha, na ótica da equipe municipal de meio ambiente, preencher a necessidade de um planejamento ambiental municipal, capaz de orientar uma política ambiental mais acurada, dadas as diversidades de um compartimento territorial para outro.

Um desafio básico para o governo municipal era a tramitação do Plano na Câmara de Vereadores, dominada pela oposição, e onde mesmo a pequena bancada eleita sob a mesma legenda do Prefeito exercia uma sustentação bissexta a seus projetos. As divergências entre Executivo e Legislativo não eram apenas ligadas a conveniências do jogo político-eleitoral, mas a compromissos com interesses e visões de mundo bastante diversos. Ao fim do primeiro ano de governo, o Executivo tivera sérias dificuldades em obter respaldo no Legislativo para encerrar um contrato lesivo ao interesse público com uma empresa que alugava as máquinas para coleta de lixo. Comprando uma dúzia de caminhões compactadores, tratores e outros veículos, o governo ainda economizaria 5 milhões de dólares ao longo dos quatro anos de administração. A Câmara criou obstáculos para esta solução, por meses, como bem documentou o jornal local (Imprensa Livre, agosto a outubro de 1997).

Temia-se, em função do histórico do grupo de vereadores, que preocupações ambientais ou de qualidade em geral pudessem ser preteridas por interesses mais imediatistas. Por outro lado, era do interesse da Administração abrir o debate para que os conteúdos técnicos do Plano fossem "digeridos" pela comunidade, tornando-se mais acessíveis e compreendidos pelos setores organizados e, gradualmente, pelo conjunto da população. Isso permitiria, inclusive, contar com respaldo para os conteúdos do Plano em sua tramitação legislativa.

O plano de discussão pública, proposto pela Prefeitura e aprovado pelo COMDURB, reconhecia este Conselho como o centro político desta nova etapa. O Conselho criou uma comissão aberta, encarregada da coordenação do processo e sustentada técnica e administrativamente pelo Executivo. Foi estabelecido um roteiro de audiências públicas ao longo do município, uma para cada bairro central de cada uma das cinco unidades de 
Saúde e Sociedade 10(1):15-31, 2001

planejamento em que o estudo do Plano Diretor dividiu São Sebastião. Ao longo de 1998, a dinâmica de discussão alternou reuniões da comissão, algumas das quais com especialistas convidados a debater em maior profundidade um determinado tema, com as audiências, em que eram expostas as diretrizes do Plano, seus principais quadros de dados e mapas, suas propostas espaciais, e as dúvidas iniciais eram tiradas. As audiências suscitavam pedidos de acesso à íntegra do Plano, o que era atendido, e com apoio da Secretaria Estadual de Meio Ambiente foram confeccionados 15000 folhetos de popularização dos conteúdos do Plano, com desenhos do artista Patrício Bisso, distribuidos nas audiências e através da rede escolar. Através da comissão, era estimulada a publicação de artigos na imprensa local ou em periódicos das entidades.

\section{TÓPICOS DE NEGOCIAÇÃO}

Procurava-se combinar, assim, momentos de divulgação e convite ao debate com outros em que pudesse haver aprofundamento e mesmo negociações. Sem que se anunciasse uma intenção de estabelecer um mecanismo formal de negociação de conflitos, eram adotados procedimentos básicos nesse sentido. Foi estabelecida uma mesa organizada, em que eram garantidos procedimentos democráticos, e trabalhava-se uma postura de respeito pelas opiniões alheias, ainda que divergentes, por parte de cada um dos interlocutores. A Prefeitura fornecia informações confiáveis para todo e qualquer setor que as demandasse. Procurava-se trabalhar encaminhamentos de soluções negociadas para pontos específicos, e, em paralelo, ampliar a compreensão sobre a importância de avançar, no município, para regras de conduta negociadas pela comunidade.

As questões levantadas nos debates, tanto os públicos como os da comissão, foram sistematizadas e apresentadas ao COMDURB, ao final de 1998. Acréscimos, modificações, novas formulações surgiram para trechos específicos. Por exemplo, o texto condenava de forma explícita a idéia de "verticalizar" o município, propondo a manutenção do limite legal de 9 metros de altura máxima para edificações, no período de vigência do Plano (até 2004) como até então a lei municipal já estabelecia. Constatado que não haveria escassez de espaço no horizonte de tempo do Plano, a idéia era evitar o "mal desnecessário" da verticalização, concentradora de pessoas e veículos numa cidade precária em saneamento e vias de tráfego, e cuja identidade paisagística se liga ao padrão "horizontal". Entre outras razões para adotar esta diretriz, apresentava-se a idéia de que sem prédios altos, a cidade ganha valor na competição pela preferência dos turistas, diferenciando-se paisagisticamente das outras cidades litorâneas. 
Incorporava-se, também, a reivindicação de hoteleiros e comerciantes da costa sul, priorizando um estudo sobre espaços marinhos adequados para estruturas de apoio ao turismo náutico. Duas idéias, em especial, representaram avanços concretos em termos de negociação : uma nova redação para o ítem resíduos sólidos e a reserva de áreas para uso turístico.

O divisor de águas na questão dos resíduos sólidos era a maneira de se referir à área de disposição final localizada no bairro da Baleia, tratada basicamente como um lixão no passado. Isso gerou movimento contra a existência dessa área entre as sociedades de amigos dos bairros próximos, desdobrando-se, inclusive, em ação judicial. É assunto de difícil equacionamento, pois simplesmente não se encontram espaços alternativos passiveis de aprovação pela CETESB, face à ocupação avançada das áreas de planície. O novo texto negociado incluiu os compromissos de sanear a área da Baleia e buscar soluções alternativas, que venham a permitir que cada região do município disponha seus resíduos dentro de seus limites.

As áreas reservadas para localização de atividades turísticas na proposta do Plano aprovada pelo COMDURB são basicamente os morros, abaixo das cotas onde se inicia o Parque Estadual, e outros espaços intermediários à sua volta. Locais de notável paisagem, abrangidos pelo tombamento, entendeu-se que sua destinação para o turismo viria proteger pelo uso mais seletivo e de baixa densidade os conjuntos naturais que se quer conservar. Essa idéia de zonas-tampão encontrou resistência entre os ambientalistas, inicialmente, por contrapor-se à sua preferência genérica pela idéia de não - uso desses espaços. Com o andamento da discussão, aparentemente ocorreu por parte destes setores um entendimento sobre a necessidade de estimular o turismo como alternativa econômica sustentável, ao mesmo tempo em que se adquiria confiança sobre a consistência global do Plano. À medida em que o conjunto de suas propostas tornava-se conhecido, o trabalho técnico angariava respeitabilidade - ainda que para determinados assuntos os conteúdos do texto pudessem ser vistos como avanços limitados, como no caso da discussão de alternativas para o saneamento básico ou para a re-configuração de alguns bairros hoje caracterizados por um desenvolvimento caótico de sua malha urbana.

\section{TURISMO X VERANISMO : A SUSTENTABILIDADE NO USO DOS RECURSOS AMBIENTAIS}

O Plano e sua discussão transformaram em assunto geral uma questão até então familiar aos técnicos ou aos iniciados em temas de meio ambiente, na região. A dinâmica 
do debate público fez aflorar a contraposição entre turismo e veranismo como vocações antagônicas ou complementares do município.

Em 1992, o plano municipal de turismo já levantara essa discussão, diferenciando o que seria o "veranismo", ou busca das residências de veraneio para compra ou aluguel (CTI,1991). Este estudo mostrava que esta opção se afirmara historicamente, aproveitando a oferta do produto sol e praia e as facilidades de acesso, acarretando benefícios econômicos mas também vários custos sociais e ambientais. $\mathrm{O}$ veranismo é um turismo fortemente sazonal, concentrando na temporada de verão, e em alguns feriados, grandes fluxos de turistas que usualmente superam largamente a oferta local de infra-estrutura e serviços. A permanência no tempo deste perfil de utilização dos equipamentos turísticos gera distorções de preços e descontinuidade das vagas de trabalho, dificultando mesmo o desenvolvimento de uma indústria do turismo. Do ponto de vista ambiental, estes períodos, em que a população do local se multiplica muitas vezes, acarretam os problemas típicos do chamado turismo de massa (RUSCHMANN,1999), com geração de poluição, descaracterização dos lugares, perda de referências culturais e perda progressiva da própria atratividade. O Plano Diretor incorporava esta visão crítica sobre o veranismo, alertando para a tendência de um uso extensivo do território para atividades imobiliárias, o que além de certos limites razoáveis acarreta uma série de impactos indesejáveis. Retomou-se assim do plano turístico a proposta de investir no desenvolvimento do turismo propriamente dito, gerando atrativos menos sazonais, como o ecoturismo, o turismo de eventos ou o turismo náutico, todos apoiados nas características geográficas e na inserção de São Sebastião nos mercados regionais.

A delimitação de zonas para urbanização e para localização de empreendimentos turísticos é uma implicação necessária desta postura nas propostas de espacialização. Os atores que vieram para a mesa de discussão ao longo de 1998 aderiram aos parâmetros propostos, percebendo as mútuas conveniências desta alteração de rumo em relação ao desenfreado uso imobiliário que prevalecera nos tempos recentes. O consenso negociado no COMDURB refletiu esta compreensão. No lance seguinte, quando o Plano tramitou na Câmara, parte deste avanço seria desbaratado por interesses que optaram por não mostrarse, delegando a garantia de seus objetivos a manobras legislativas, como se verá a seguir.

\section{O ATOR OCULTO: A TRAMITAÇÃO DO PLANO NO LEGISLATIVO}

A Prefeitura enviou à Câmara como projeto de lei o texto aprovado unanimemente pelo COMDURB. Imediatamente, alguns vereadores levantaram a bandeira de autorizar prédios altos, para "gerar empregos e solucionar a questão da moradia popular". Uma forte 
campanha contra essa idéia se sucedeu. Depois de reunir o Conselho e propor uma mobilização ampla, o Prefeito passou a colocar anúncios de esclarecimento nos jornais e na rádio local. As sociedades da costa sul começaram uma campanha via Internet que mostrou o potencial mobilizador deste meio, resultando em mais de 10 mil assinaturas contra a verticalização. O MOPRESS e outras entidades locais, como o movimento Voto Consciente, fizeram concurso de redações estudantis sobre o tema. Televisões regionais, jornais de São Paulo, revistas semanais, garantiram repercussão ao movimento. A penetração da campanha pode ser medida por sinais como os trabalhos de estudantes da escola municipal mostrados na feira da educação em novembro, com desenhos e frases optando por uma cidade sem prédios.

O debate na Câmara se resumiu a este tema, e ao final os vereadores, fortemente pressionados, recuaram, abandonando a proposta. Contudo, sem qualquer debate público prévio, emendas assinadas pela totalidade dos vereadores alteraram alguns pontos do Plano, já em plenário de votação. A principal delas simplesmente trocou um mapa das zonas de usos propostas, por outro. As principais mudanças eram a redução de algumas áreas de proteção de mananciais; a "liberação" para urbanização de uma enorme área de um único proprietário na costa sul; e o condicionamento a "autorizações legislativas", caso a caso, para uso das zonas turísticas.

Ficou claro que a polarização em torno da verticalização serviu em parte como manobra diversionista para os vereadores que representavam interesses específicos, vinculados a atividades imobiliárias. Tomando conhecimento da manobra, a Prefeitura denunciou-a ao COMDURB, antes da sanção da lei. A disposição manifestada então de forma generalizada, pelas entidades, foi de retomar a luta para restaurar o mapa original.

\section{PARA UM BALANÇO DA EXPERIÊNCIA: ATÉ ONDE AVANÇOU A NEGOCIAÇÃO}

Sabia-se que a atual Câmara de São Sebastião tem forte predominância de interesses específicos, inclusive os imobiliários. Sendo ademais uma Câmara de oposição, certamente uma proposta de Plano Diretor enviada sem ampla discussão prévia estaria destinada à retaliação ou à rejeição pura e simples.

A estratégia de buscar a mobilização de atores que, no dia a dia, participam das decisões de gestão ambiental e urbana, revelou-se adequada para relativizar o peso decisório 
de um conjunto de políticos desacostumados à consulta popular, embora oriundos do voto direto. A criação deste novo tipo de espaço público, onde agem setores governamentais, privados e não governamentais, parece mesmo essencial para que vigore um sistema democrático, pois equilibra o confronto entre um governo eleito com metade dos votos válidos e um legislativo em que a soma dos votos dados a seus membros não chega a 15 \% dos votantes. A diferença de parâmetro dos eleitores ao definir preferências nos votos majoritário e proporcional e a fragilidade das legendas partidárias são dados de uma realidade que se caracteriza por um equilíbrio delicado entre poderes igualmente legítimos em sua origem e função no regime político brasileiro.

A busca da participação em fóruns como o COMDURB de São Sebastião pode representar um mecanismo de busca cotidiana da legitimidade, capaz de aproximar a política e a gestão pública do cidadão. Isso possibilita um processo de amadurecimento político das entidades e grupos da sociedade civil, a partir do próprio reconhecimento dos novos sujeitos coletivos propiciado pela dinâmica desta "institucionalidade ampliada", como bem destaca LEILA FERREIRA (1997).

Concluida esta etapa da discussão e votação do Plano Diretor de São Sebastião, pode-se dizer que iniciou-se nesta comunidade um processo de negociação de conflitos. Houve de fato transações entre os diferentes atores, tão importantes em si - na medida em que permitiram um acordo de sustentação ao Plano - quanto por significarem a compreensão de que é possivel e necessário transacionar para avançar na busca de novos equilíbrios entre desenvolvimento e qualidade ambiental.

Este começo de processo de negociação abre uma possibilidade fundamental para o município, se for claramente percebido pelos atores que inflluenciam na gestão ambiental local e regional. O município tem vivido um impasse, com os novos projetos econômicos tendo grande dificuldade de aprovação, fenômeno em que contribuem tanto as preocupações ambientais legítimas quanto as limitações operacionais da burocracia. Se os setores que defendem a idéia de qualidade ambiental não têm força para conduzir o processo decisório, têm peso suficiente para "empatar" iniciativas. O Plano Diretor e sua discussão apontaram uma alternativa a esta situação de equilíbrio precário, desenhando um horizonte em que o turismo puxa novos padrões de qualidade para as demais atividades e confere dinamismo à economia, num cenário em que a qualidade ambiental é atributo de competitividade do lugar (SANTOS, 1996). 
A limitação do processo de negociação se liga basicamente ao fato de que nem todos os interlocutores se sentaram à mesa. A principal dificuldade é identificar um interlocutor que congregue os interesses imobiliários, que apresentam-se atomizados. Houve empresários do ramo participando e suportando galhardamente o tom crítico dos ambientalistas. Outros, preferiram manter-se fora de uma discussão aberta, contando com votos cativos no legislativo. Esta estratégia foi parcialmente eficaz no curto prazo; mas não seria seguro apostar, depois da mobilização construida em dois anos de debate e campanhas, que as regras assim forjadas terão vida longa.

\section{REFERÊNCIAS BIBLIOGRÁFICAS}

BECKER, B. K. Repensando a questão ambiental no Brasil a partir da geografia política. In: Leal, M. C. et al., org. Uma análise interdisciplinar. São Paulo. Hucitec/Abrasco, 1992. (Saúde, Ambiente e Desenvolvimento, vol. 1).

BIDWELL, R. From political goals to practical application: making sustainability operational. London, Environmental Resources Management, 1993.

BLAUTH, P. R. \& GONÇALVES, G. O. Separação domiciliar do lixo: por um destino final desde o início. São Paulo, 1990. [Texto para Revista do CEPAM].

CÂMARA, I. G. Plano de ação para a Mata Atlântica. São Paulo, SOS Mata Atlântica, 1992.

CEPAL - COMISION ECONOMICA PARAAMERICA LATINA Y EL CARIBE. Dourojeanni, A. Procedimientos de gestión para un desarrollo sustentable: aplicables a municipios, microrregiones y cuencas. Santiago de Chile, 1993.

COMISSÃO MUNDIAL SOBRE AMBIENTE E DESENVOLVIMENTO. Nosso futuro comum. Rio de Janeiro, Ed. Fundação Getúlio Vargas, 1988.

CTI - Consultoria Turística Integrada. Plano de desenvolvimento turístico do município de São Sebastião. São Sebastião, 1991. 2 v.

CUNHA, I. A. Sustentabilidade e poder local: a experiência de política ambiental em São Sebastião, costa norte de São Paulo (1989-1992). São Paulo, 1996. [Tese de Doutorado, - Faculdade de Saúde Pública da USP].

DIEGUES, A. C. As áreas naturais protegidas: o mito do paraiso desabitado. Caxambu, 1994. [Apresentado ao $18^{\circ}$ Encontro Anual da ANPOCS, Caxambú/MG, 1994]. 
Saúde e Sociedade 10(1):15-31, 2001

DIEGUES, A. C. A construção de uma nova ciência da conservação para as áreas protegidas nos trópicos : a etno-conservação. Debates Socioambientais, 5(13):9-11, 1999.

FERREIRA, L.C. \& JACOBI, P. As cidades e a sustentabilidade . Debates Socioambientais, 4(11):6, 1999.

FERREIRA, L. C. Sustentabilidade e democracia no poder local. Ambiente e Sociedade, 1(1):63-80, 1997.

FUNDAP - FUNDAÇÃO DO DESENVOLVIMENTO ADMINISTRATIVO. Curso de Especialização em Ciências e Técnicas de Governo - Estrutura curricular. São Paulo, 1998.

GUIMARÃES, R. P. Modernidad, medio ambiente y etica: un nuevo paradigma de desarrollo. Ambiente e Sociedade, 1(2):5-24, 1998.

HOGAN, D. J. Crescimento populacional e desenvolvimento sustentável. Lua Nova, (31):57$77,1993$.

HUERTAS, F. Entrevista com Matus: o método PES. São Paulo, Fundap, 1996.

IBASE. Meio ambiente e democracia . Rio de Janeiro, 1992.

IBASE. Conflitos sociais e meio ambiente: desafios políticos e conceituais. Rio de Janeiro, 1995.

IMPRENSA Livre - edições de agosto a outubro de 1997. Jornal Imprensa Livre, São Sebastião.

JACOBI, P. Interdisciplinaridade e meio ambiente. Debates Socioambientais, 3(10):1, 1998.

MATUS, C. Chimpanzé, Maquiavel e Gandhi: estratégias políticas. São Paulo, Fundap, 1996.

MATUS, C. Adeus, senhor presidente: governantes governados. São Paulo, Fundap, 1997.

MORAES, A. C. R. Meio ambiente e ciências humanas. São Paulo, Hucitec, 1994.

MORAES, A. C. R. Os impactos da política urbana sobre a zona costeira . Brasília, Ministério do Meio Ambiente, dos Recursos Hídricos e da Amazônia Legal , 1995.

PÁDUA, J. A. Origens da ecologia política no Brasil. Rio de Janeiro, Universidade Estadual do Rio de Janeiro, s d. [documento interno] 
PREFEITURAMUNICIPAL DE SÃO SEBASTIÃO. Plano Diretor 1998-2004. São Sebastião, 1998.

RUSCHMANN, D. Turismo e planejamento sustentável: a proteção do meio ambiente. Campinas, Papirus Ed., 1999.

SACHS, I. Ecodesenvolvimento: crescer sem destruir . São Paulo, Ed. Vértice, 1986.

SACHS, I. Estratégias de transição para o século XXI: desenvolvimento e meio ambiente. São Paulo, Studio Nobel/ Fundap, 1993.

SANTOS, M. A natureza do espaço; técnica e tempo; razão e emoção. São Paulo, Ed. Hucitec, 1996.

SOS Mata Atlântica - Boletim Informativo, 1(10). São Paulo, out/nov 1999.

SUSTAINABILITY CHALLENGE FOUNDATION. First International Programme on the Management of Sustainability: selected readings. Nijenrode University, The Netherlands Business School, 1994 .

SUSSKIND, L. \& Field, P. Dealing with an angry public: the mutual gains approach to resolving disputes. New York, The Free Press, 1996.

VIOLA, E. J. A evolução das políticas ambientais no Brasil , 1971-1991: do bissetorialismo preservacionista para o multissetorialismo orientado para o desenvolvimento sustentável. In: Hogan, D. J.; Vieira, P. F., org. Dilemas socioambientais e desenvolvimento sustentável . Campinas, Ed. Unicamp, 1992. 73-102. 


\section{ENVIRONMENTAL CONFLICT ON THE COAST OF SÃO PAULO: SÃO SEBASTIAO'S DIRECTIVE PLAN}

SUMMARY: Environmental problems may be understood as conflicts between different actors. This represents an alternative approach related to the conceptualy poorer opposition between nature and anthropic actions, which generalize to whole society predatory patterns of relationship with environment. Dealing with the concept of environmental conflicts, we may recognize different forms of society-nature relation, and diverse concrete interests, associated to the various uses of environmental resources. This opens, besides, the possibility to understand the conflicts dynamics as something that may contribute building sustainability.

This text intends to describe and discuss an environmental conflict episode, the public debate, and negotiation and votation of Master Plan of São Sebastião, a city in São Paulo northern coast. The objective is to discuss the gains in terms of conflict mediation utilyzing consensus building techniques, establishing relations between this process and the local political dynamic, with special attention to Executive and Legislative power roles as participative mechanisms. The main question related to the sustainability building agenda is the competition between a global tourism policy and summer holidays demand for the use of territory and its resources.

KEY WORDS: environmental conflicts; sustainability and consensus building; tourism and environmental conflicts 